\title{
Impact of Intellectual Capital and Social Capital on the Human Resource Performance in the Chemical Industries in Pakistan
}

\author{
Muhammad Hassaan Khan ${ }^{1, *}$, Ibrahim hassan ${ }^{2}$, Muhammad Nasir Khan ${ }^{3}$, Nouman Ahmad ${ }^{2}$, \\ Zarnab Qadeer ${ }^{2}$ \\ ${ }^{1}$ Faculty of Management Sciences, University of Central Punjab, Pakistan \\ ${ }^{2}$ Faculty of Management Sciences, Superior University, Pakistan \\ ${ }^{3}$ Faculty of Engineering, The University of Lahore, Pakistan
}

Copyright $\mathrm{O} 2016$ by authors, all rights reserved. Authors agree that this article remains permanently open access under the terms of the Creative Commons Attribution License 4.0 International License

\begin{abstract}
An emerging knowledge economy creates major challenges for human resource development (HRD) in organisations. The purpose of this paper is to identify some of these challenges and explore their implications for HRD professionals. The paper takes the form of a literature review to contribute to the ongoing debate about HRD's changing role and tasks. Having set the organisational process of HRD in the context of a knowledge economy and of macro-level socio-economic policy, we explore notions of strategy, structure and knowledge and their implications for those with HRD responsibilities in organisations. We identify and discuss four major challenges that confront the HRD function, and conclude that a knowledge economy invites HRD professionals to play a crucial role in the transformation of organisations. As working, learning and knowing are closely related processes, HRD could become the integrating vehicle for generating human and social capital: primary driving forces in a knowledge society.
\end{abstract}

Keywords Information Technology, Customer Service Management, Suppliers, Order Fulfillment, Supply Chain Performance

\section{Introduction}

The term "Intellectual Capital" $[1,2]$ collectively refers to all resources that determine the value of an organization, and the competitiveness of an enterprise. Understandably, the term "intellectual capital" from a human resources perspective is not easily translatable into financial terms. For all other assets of a company, there exist standard criteria for expressing their value. Perhaps, this term could more appropriately term a "non-financial asset." In an article written by Paolo Magrassi titled Taxonomy of Intellectual
Capital", [3, 4, 5], Mr. Magrassi defines human capital as "the knowledge and competencies residing with the company's employees" and defines organizational intellectual capital as "the collective know-how, even beyond the capabilities of individual employees, that contributes to an organization."

Although there has been an increasing interest in intellectual capital and an increasing interest in how it might be managed, there has been little written to succinctly describe and define the concept. This article is intended to describe where and how it fits into the collective knowledge of an organization. Therefore, this article is intended for academicians and practitioners alike. It is intended to provide an overview of intellectual capital, where it fits into an organization, what the component elements of it are, and what might be done to manage them $[6,7]$.

Intellectual capital can include the skills and knowledge that a company has developed about how to make its goods and services [7, 8]. It also includes insight about information pertaining to the company's history; customers; vendors; processes; stakeholders; and all other information that might have value for a competitor that, perhaps, is not common knowledge. Intellectual capital is therefore, not only organizational knowledge, it is also industry knowledge. It is the combination of both cognitive knowledge and intuitive/experience-related knowledge.

Human resource (HR) configurations facilitate flow of knowledge, which leads to sustainable competitive advantage. HR is always on the front line in developing the knowledge base in the organization as the people dimension play key role for human resource management and human resource development for effective knowledge management practices. HR practices have a central importance in knowledge intensive industries because they have immediate effect on the organization's key resource, its stock of intellectual talent. HR strategy drives the long term strategy 
of the business $[9,10]$. HR practices if chosen deliberately and used strategically can maintain strong organizational boundaries and promote high levels of organizational and professional identity and more specifically it encourages the retention of staff in a highly competitive industry. The architectural perspective of $\mathrm{HR}$ can be extended to incorporate social capital as a critical component for managing the flow of knowledge between employees to serve as a competitive advantage. HR practices and processes influence creation and sustenance of social capital. HR practices directed at creating and sharing knowledge throughout the firm accounts for new value creation. In the knowledge era, the traditional factors of production of land, labour and capital are being replaced by the creation of value through knowledge [11-15] and firms are becoming embedded within a complex web of interconnections that span markets, governments and communities.

Employees have extensive knowledge about their job, the business processes, the data that supports their Jobs including how to make things happen, and what works best. Unfortunately, in most instances today their knowledge has not been captured, transferred, or made available to others. In a recent "Business Week" article [16, 17] one of the publications' editors, Deborah Stead, writes about the importance of identifying and recognizing the importance of preserving intellectual capital. In her article [18] titled "Are Your Employees Just Biding Their Time?" the article discusses that the current unemployment rate across the country has scared working Americans into hanging on to their jobs at all costs. However, the article goes on to express that employers that do not fully recognize the importance of employees should not count on workers' loyalty to outlast the recession.

The constantly changing business environment requires firms to strive for superior competitive advantages via dynamic business plans which incorporate creativity and innovativeness. This is essentially important for their long term sustainability. Undoubtedly, human resource input plays a significant role in enhancing firms' competitiveness [19]. At a glance, substantial studies were carried out on human capital and their implications on firm performance were widely covered and obviously, human capital enhancement will result in greater competitiveness and performance [20-22]. Meantime, there is a significant relationship between innovativeness and firm performance under the human capital philosophy $[10,23]$. In relation to this, the definition of firm performance could vary from one and another. Nonetheless, some clear definitions of firm performance in the context of human capital enhancement could be put forward. In some cases, financial performance measures such as percentage of sales resulting from new products, profitability, and capital employed and returns on assets (ROA) [24, 11-12]. Besides, return on investment (ROI), earnings per share (EPS) and net income after tax (NIAT) can also be used as measures of financial performance [13]. Interestingly, researchers also tend to benchmark managerial accounting indicators against the financial measures in six dimension; 'workers compensation' (workers' compensation expenses divided by sales); 'quality' (number of errors in production); 'shrinkage' (e.g. inventory loss, defects, sales return); 'productivity' (payroll expenses divided by output); 'operating expenses' (total operating expenses divided by sales) [14]. On the other hand, firm performance can also be measured using 'perceived performance approach' (also referred to as subjective performance measure) where Likert-like scaling is used to measure firm performance from the top management perspectives [15].

Traditionally, capital has been classified in form of natural capital, physical capital and human capital. These capitals together develop the Wealth of Nations and make the base of development and economic growth. In this process the composition of capitals is changed. Some of natural capitals are used and then transform to physical capitals. Physical capitals break up as well and it is expected that some effective alternatives will be created for them by technology. It is now accepted that these three types of capital identify only some parts of economic growth process, because they ignore how economic players interact and how they organize themselves to create growth and development. Here, the missing link is social capital. There is a little disagreement about the role of social capital. However, there is no consensus about which aspects of dimensions of these interactions and organization merit the name of social capital and also about the validity of the term "capital" to describe this issue [16].

Presented definitions for social capital are numerous and different. In 1998 the World Bank defines social capital as follows: "Social capital includes institutions, relationships, views and values in a given society that govern the actions and reactions between people and have some shares in the economic and social development. But, social capital is not a simple sum of institutions that include society; instead it is a mortar that links the mentioned institutions to each other. At the same time, social capital includes shared values and norms essential for social behavior that is reflected in individuals' personal relationships, their trust in each other and shared sense of civic responsibility, something that makes society more than and beyond the sum of individuals [17].

Also, in some researches, social capital is determined by trust [18-21]. Some studies have introduced it with networks [7] and norms [12-15]. In order to prevent plurality in social capital definition, distinguish between sources and results is necessary. It should be noted that the review of social capital resources is more in social sciences domain; but the results of social capital include many sciences including economics. In fact the sources of social capital are those networks and institutions that are formed by relationships govern among them and the results of this capital i.e. norms, trends and values. In other words, it is by attendance in the networks and having a continuous relationship with others that the outcomes of social capital including trust and practice in norms are achieved. Therefore, the sources of social capital 
should be applied so that its results to be achieved. These sources have wide range of results that depending on the circumstances, they can be positive or even negative [12]

In this world the concept of social capital can take on a whole new dimension for the - firm $\|$ as it focus on the nature and strength of relationships and the communication flows in which individuals and organizations are embedded. Organization achieves excellent SC by collectively maximizing its external, internal and human capital. Nahapiet and Ghoshal in his seminal work on -Social Capital, Intellectual Capital, and the Organizational Advantage [13, 17] proposed that a firm's capability to create SC provides a conducive environment for IC creation and hence organization performance. Hence Social capital requires attention to be paid to the relationships which shape the realization of human capital's potential for the individual and collectively. With this backdrop the paper examines the effects social capital on organizational performance. At the organizational level, social capital has been used to describe the aggregate form and nature of relationships among organizational members $[11,14$, and 16] as well as the linkages between the organization and its external stakeholders, competitors, or partners [12-13]. The present study focuses on the relationships among individual members-- referred to as internal social capital- and the basic premise is that HR Configuration and HR practices adds appreciably to organization level of social capital and which again enhance performance at the organizational level. We test our hypotheses from six Indian IT organizations where we collected data from 466 respondents from lower, middle and upper level executives.

Organizational social capital emphasizes on the social dimension of "together we are stronger" saying in the organization. In other words, organizational social capital can be expressed as the cooperation in addressing to a common goal among the employees in the organization, strong social networks, and breathing the same air in an atmosphere of confidence and working enthusiasm that is a reflection of "robustness of a chain is as much as the robustness of the weakest link" saying. In the study, organizational social capital is introduced conceptually as well as it is noted that it is a phenomenon that has the characteristic of catalyst to be used by the human resource managements in increasing competition nowadays.

\section{Research Methods}

Target population for the research is the chemical industry of Pakistan.

\subsection{Target Population and Sample Size}

Target population for the research was chemical industry of Pakistan. Non-probability Sampling (Convenience sampling) technique is used. This research is conducted from chemical industry on Lahore only. Sample size was 150 and response rate was $89 \%$.

\subsection{Data Collection Tools}

The tool selected for the collection of data of research was questionnaire. Close-ended questionnaire having structured questions with five point Likert scale ranging from "Strongly Agree" to "Strongly Disagree" was used as the instrument of data collection. The questionnaire was formulated on the basis of the different variables of HRD. Each variable was asked in both positive and negative direction.

The study could be beneficial for organizations and as well as for industrial growth. This study tries to find out what the impact of IT on SCM. This will lead to greater organizational growth and performance with the latest technologies and accessibility. Institutes can invest more in IT facilities to enhance performance and produce better results. This study will also open new doors for future research. There could be certain questions raised such as

1. What is the impact of IT in Supply Chain Performance in a chemical industry of Pakistan?

2. What is the impact of Information Technology (IT) in Suppliers performance in a chemical industry of Pakistan?

3. What is the impact of Information Technology (IT) in Customer Service Management performance in a chemical industry of Pakistan?

4. What is the impact of Information Technology (IT) in Order Fulfillment performance in a chemical industry of Pakistan?

\section{Analysis}

SPSS would be used to analyze the data. Hypothesis is defined for the analysis. Factor analysis, descriptive analysis, Regression Analysis including demographic is used in this research.

\subsection{Hypothesis}

- $\mathrm{H}_{1 \mathrm{a}}=$ There is a relationship between Supply Chain Performance and Customer Service Management.

- $\mathrm{H}_{0}=$ There in no relationship between Supply Chain Performance and Customer Service Management.

- $\mathrm{H}_{1 \mathrm{~b}}=$ There is a relationship between Supply Chain Performance and Suppliers.

- $\mathrm{H}_{0}=$ There in no relationship between Supply Chain Performance and Suppliers.

- $\mathrm{H}_{\mathrm{lc}}=$ There is a relationship between Supply Chain Performance and Order Fulfillment.

- $\mathrm{H}_{0}=$ There in no relationship between Supply Chain Performance and Order Fulfillment.

\subsection{Limitations \& Delimitations}

The focus of this study is limited to supply chain managers 
and executives of chemical industry of Pakistan thus cannot be generalized on the other sectors. There can be likewise limitation connected with time along with human resources. That's why almost all demographic and also geographic variables inside Pakistan tend to be not covered.

The demographic view is given in Table 1. Validity and reliability analysis is provided in Table 2 . Table 3 gives the summary of KMO \& Bartlett's Test. Eigen Values and Total Variance Explained in Table 4. We keep the supply chain performance is dependent variable and based on the dependent variable regression and statistics analysis is provided in Table 5 and 6 respectively.

Table 1. Demographic View

\begin{tabular}{|c|c|c|c|}
\hline & & Frequency & $\%$ \\
\hline \multirow{3}{*}{ Industry Type } & Service & 4 & 3 \\
\hline & Manufacturing & 119 & 88.8 \\
\hline & Retailers & 11 & 8.2 \\
\hline \multirow{2}{*}{ Sector } & Public & 2 & 1.5 \\
\hline & Private & 132 & 98.5 \\
\hline \multirow{3}{*}{ Company Operations } & Regional & 7 & 5.2 \\
\hline & National & 126 & 84 \\
\hline & World Wide & 1 & 0.7 \\
\hline \multirow{5}{*}{ No. of Employees } & $0-100$ & 15 & 11.2 \\
\hline & $101-300$ & 47 & 35.1 \\
\hline & $301-500$ & 47 & 35.1 \\
\hline & $501-1000$ & 14 & 10.4 \\
\hline & 1000 - more & 11 & 8.2 \\
\hline \multirow{3}{*}{ No. of Customers } & $0-500$ & 20 & 14.9 \\
\hline & $501-1000$ & 13 & 9.7 \\
\hline & $1001-$ more & 101 & 75.4 \\
\hline \multirow{3}{*}{ No. of Suppliers } & $0-100$ & 125 & 93.3 \\
\hline & $101-250$ & 5 & 3.7 \\
\hline & $251-$ more & 4 & 3 \\
\hline \multirow{4}{*}{$\begin{array}{l}\text { Total Revenue: } \\
\text { (Per Month) }\end{array}$} & $\$ 50$ million or less & 28 & 20.9 \\
\hline & $\$ 50$ million or less & 81 & 60.4 \\
\hline & $\$ 100$ million- $\$ 500$ million & 21 & 15.7 \\
\hline & $\$ 500$ million - $\$ 1$ billion & 4 & 3 \\
\hline
\end{tabular}

Table 2. Validity and Reliability

\begin{tabular}{|c|c|c|c|}
\hline Variable & Valid N & Cronbach's Alpha & No. of Items \\
\hline Intellectual capital & 250 & 0.711 & 5 \\
\hline social capital & 250 & 0.719 & 6 \\
\hline Human Resource Performance & 250 & 0.778 & 6 \\
\hline
\end{tabular}

Table 3. KMO \& Bartlett's Test

\begin{tabular}{|c|c|c|c|c|}
\hline Variables & No. of Items & $\begin{array}{c}\text { KMO measure of sampling } \\
\text { Adequacy }\end{array}$ & $\begin{array}{c}\text { Bartletts Test of Sphericity } \\
\text { Chi-Squre }\end{array}$ & Significance \\
\hline Intellectual capital & 5 & 0.706 & 129.468 & 0.00 \\
\hline social capital & 6 & 0.749 & 118.713 & 0.00 \\
\hline $\begin{array}{c}\text { Human Resource } \\
\text { Performance }\end{array}$ & 6 & 0.738 & 230.584 & 0.00 \\
\hline
\end{tabular}

Table 4. Eigen Values and Total Variance

\begin{tabular}{|c|c|c|c|c|}
\hline \multirow[b]{2}{*}{ Construct } & \multirow[b]{2}{*}{ Components } & \multicolumn{3}{|c|}{ Initial Eigen Values } \\
\hline & & Total & $\%$ of Variance Explained & $\begin{array}{c}\text { Cumulative \% of Variance } \\
\text { Explained }\end{array}$ \\
\hline Intellectual capital & Comp 1 & 2.888 & 48.137 & 48.137 \\
\hline social capital & Comp 1 & 2.154 & 48.497 & 48.497 \\
\hline \multirow{2}{*}{$\begin{array}{l}\text { Human Resource } \\
\text { Performance }\end{array}$} & Comp 1 & 2.450 & 48.999 & 48.999 \\
\hline & Comp 2 & 1.021 & 20.426 & 69.425 \\
\hline
\end{tabular}


Table 5. Regression Analysis

\begin{tabular}{|c|c|c|c|}
\hline Regressor & Coefficient & Standard Error & T-Ratio \\
\hline Intellectual capital & 1.619 & 0.493 & 3.284 \\
\hline social capital & 1.786 & 0.536 & 3.332 \\
\hline Human Resource Performance & 1.587 & 0.396 & 3.168 \\
\hline
\end{tabular}

Table 6. Statistics Analysis

\begin{tabular}{|c|c|c|c|c|}
\hline Model & R Square & Adj. R Square & F-Statics & Prob. (F-Statics) \\
\hline Intellectual capital & 0.236 & 0.206 & 7.920 & 0 \\
\hline social capital & 0.270 & 0.211 & 4.550 & 0 \\
\hline Human Resource Performance & 0.267 & 0.215 & 6.920 & 0 \\
\hline
\end{tabular}

\section{Conclusions and Recommendations}

When an organization is understood as an evolving system of knowledge production and application, HRD professionals have the opportunity to become strategic players. To do that, they will need mastery of expertise similar to that possessed by the HR professionals identified in recent research who are carrying strategic roles in globalizing organizations. That expertise incorporates;

- Ability to deal with social and cultural factors of learning situated in workplace communities of practice

- Skills in coaching, counseling and mentoring individuals and teams in knowledge work

- The ability to think strategically, to work in virtual contexts and to tolerate ambiguities in new business situations

- The ability to work in many overlapping partnerships to create and sustain an organizational culture favorable to learning that can drive improvement and innovation.

In knowledge-creating organizations HRD activity should not primarily focus on formal classroom training but on a variety of forms of work-related learning in order that organizational progress and individual potential can be enhanced through the competence, adaptability, collaboration and knowledge productivity of all organizational members.

This study get data consist of 8 chemical industries, to get more accurate results researcher can use large sample size Service Management (CSM), Suppliers, and Order Fulfillment (OF) are three variable used to measure the supply chain performance, but 3rd Party Logistics Providers (3PLP), Warehousing, Inventory Management or other variables can use for further research in Pakistan

We conclude that the emergence of a knowledge economy offers exciting opportunities to the HRD profession, and to those involved in the education and continuing development of its members. We believe that the primary task is to work with organizational stakeholders to create a synergy between the learning, development and knowledge-creating capability of all organizational members, the thrust of strategizing and organizing, and the progress of the organization as its boundaries grow ever more fluid in a turbulent world.

\section{Acknowledgements}

We are very grateful to experts for their appropriate and constructive suggestions to improve this research journey.

\section{REFERENCES}

[1] Ashton, D., Sung, J., Raddon, A. and Powell, M., National frameworks for workplace learning'. In Workplace Learning in Europe [summary of the European Workplace Learning Seminar, London, 2 April (2001). London: Chartered Institute of Personnel and Development, pp. 35-60.

[2] Baum, J. A. C., Calabrese, T. and Silverman, B.S., 'Don't go it alone: alliance network composition and startups' performance in Canadian biotechnology'. Strategic Management Journal. Vol. 21, 3: 2000), pp. 267-81.

[3] Bettis, R.A. and Hitt, M.A., The new competitive landscape'. Strategic Management Journal, Summer Special Issue. Vol. 16: (1995), pp. 7-19

[4] Bournois, F., Chauchat, J-H. and Roussillon, S., Training and management development in Europe'. In C. Brewster and A. Hegewisch (eds) Policy and Practice in European Human Resource Management: The Price Waterhouse Cranfield Survey. London: Routledge, (1994), pp. 122-138.

[5] Brewster, C., Strategic Human Resource Management: the value of different paradigms'. In R.S. Schuler and S.E. Jackson (eds) Strategic Human Resource Management. Oxford: Blackwell, (1999), pp. 356-372.

[6] Brewster, C., Harris, H. and Sparrow, P., Globalising HR: Executive Briefing. London: Chartered Institute of Personnel and Development, (2002).

[7] Cappelli, P., Rethinking Employment'. British Journal of Industrial Relations. Vol. 33, 4: (1995), pp. 563-602.

[8] Chandler, A.D., Strategy and Structure: Chapters in the History of the American Industrial Enterprise. Cambridge, Mass: MIT Press, (1962).

[9] Chartered Institute of Personnel and Development, Training 
and Development 2002: Survey Report. London: (2002).

[10] Child, J., Organization: a Guide to Problems and Practice. London, Harper and Row, (2002).

[11] Cohen, W.M. and Levinthal, D.A., Absorptive capacity: a new perspective on learning and innovation'. Administrative Science Quarterly. Vol. 35, 1: (1990), pp. 128-52.

[12] Drucker, P., New templates for today's organizations'. Harvard Business Review. Vol. 52, (1974), pp. 1:45.

[13] Eisenhardt, K.M. and Santos, F.M., Knowledge-based view: a new theory of strategy. In A. Pettigrew, H. Thomas and R. Whittington (eds) Handbook of Strategy and Management. London: Sage, (2002), pp.139-164.

[14] Elfring, T. and Volberda, H.W., Multiple futures of strategy synthesis: shifting boundaries, dynamic capabilities and strategy configurations'. In H.W. Volberda and T. Elfring (eds) Rethinking Strategy. London: Sage, (2001), pp. 245-285.

[15] Field, J., Lifelong learning and the new educational order. Stoke on Trent: Trentham Books. (2000).

[16] Ghoshal, S. and Bartlett, C.A., Linking organizational context and managerial action: the dimensions of quality of management'. Strategic Management Journal, Summer Special Issue. Vol. 15: (1994), pp. 91-112.

[17] Ghoshal, S. and Bartlett, C.A., The new moral contract: guaranteeing employability'. 20th Anniversary Euroforum Conference: Strategic Leadership Programme. London Business School, 15-16 September (1995).
[18] Hansen, M.T., Nohria, N. and Tierney, T., What's your strategy for managing knowledge?' Harvard Business Review. March-April: (1999), pp.106-116.

[19] Harrison, R., Learning and Development. 3rd edn. London: Chartered Institute of Personnel and Development. (2002).

[20] Mehwish Mumtaz, Aleena Mumtaz, Muhammad N. Khan, Energy Aware Routing Using Improved LEACH Protocol, Universal Journal of Communications and Network 3(3), (2015), pp. 64-67.

[21] M. Nasir Khan, Mahnoor and Fatima, "Implementation of Smart Homes and Industrial Automation System with secure communication over GSM", Universal Journal of Electrical and Electronic Engineering Vol. 3(4), pp. 125-131.DOI: 10.13189/ujeee.2015.030403.

[22] Aamir Hayat and Muhammad Nasir Khan, "Speed Control and Power Factor Improvement of Single Phase AC Motor," Universal Journal of Electrical and Electronic Engineering, pp. 328-336, vol. 2, no. 8, Dec. 2014.

[23] M. Mumtaz, A. Mumtaz and Muhammad N. Khan, "Energy Aware Routing Using Improved LEACH Protocol", Universal Journal of Communications and Network 3(3): 64-67, 2015, DOI: 10.13189/ujen.2015.030302.

[24] Muhammad N. Khan, Noor M. Sheikh "Design and development of onboard phase modem for S-band transponder" Journal of New Horizons in Science \& Technology 2012 Canada, vol.1, no. 1, pg.06-11, March, 2012. 